\title{
Nicotinamide polymeric nanoemulsified systems: a quality-by-design case study for a sustained antimicrobial activity
}

This article was published in the following Dove Press journal:

International Journal of Nanomedicine

12 April 2016

Number of times this article has been viewed

\author{
Ahmed S Zidan ${ }^{1,2}$ \\ Osama AA Ahmed ${ }^{1,3}$ \\ Bader M Aljaeid' \\ 'Department of Pharmaceutics \\ and Industrial Pharmacy, Faculty of \\ Pharmacy, King Abdulaziz University, \\ Jeddah, Kingdom of Saudi Arabia; \\ ${ }^{2}$ Department of Pharmaceutics \\ and Industrial Pharmacy, Faculty of \\ Pharmacy, Zagazig University, Zagazig, \\ ${ }^{3}$ Department of Pharmaceutics \\ and Industrial Pharmacy, Faculty \\ of Pharmacy, Minia University, \\ Minia, Egypt
}

\begin{abstract}
Nicotinamide, the amide form of vitamin B3, was demonstrated to combat some of the antibiotic-resistant infections that are increasingly common around the world. The objective of this study was to thoroughly understand the formulation and process variabilities affecting the preparation of nicotinamide-loaded polymeric nanoemulsified particles. The quality target product profile and critical quality attributes of the proposed product were presented. Plackett-Burman screening design was employed to screen eight variables for their influences on the formulation's critical characteristics. The formulations were prepared by an oil-in-water emulsification followed by solvent replacement. The prepared systems were characterized by entrapment capacity (EC), entrapment efficiency (EE), particle size, polydispersity index, zeta potential, transmission electron microscopy, Fourier transform infrared spectroscopy, differential scanning calorimetry, powder $\mathrm{X}$-ray diffraction, in vitro drug release, and their antibacterial activity against bacterial scrums. EC, EE, particle size, polydispersity index, zeta potential, and percentage release in 24 hours were found to be in the range of $33.5 \%-68.8 \%, 53.1 \%-67.1 \%, 43.3-243.3 \mathrm{~nm}, 0.08-0.28$, 9.5-53.3 mV, and 5.8\%-22.4\%, respectively. One-way analysis of variance and Pareto charts revealed that the experimental loadings of 2-hydroxypropyl- $\beta$-cyclodextrin and Eudragit ${ }^{\mathbb{B}} \mathrm{S} 100$ were the most significant for their effects on nicotinamide EC and EE. Moreover, the polymeric nanoemulsified particles demonstrated a sustained release profile for nicotinamide. The Fourier transform infrared spectroscopy, differential scanning calorimetry, and X-ray diffraction demonstrated a significant interaction between the drug and 2-hydroxypropyl- $\beta$-cyclodextrin that might modulate the sustained release behavior. Furthermore, the formulations provided a sustained antibacterial activity that depended on nicotinamide-loading concentration, release rate, and incubation time. In conclusion, the study demonstrated the potential of polymeric nanoemulsified system to sustain the release and antibacterial activity of nicotinamide.
\end{abstract}

Keywords: nicotinamide, polymeric nanoemulsified systems, Plackett-Burman design, antibacterial activity, sustained release

\section{Introduction}

Nicotinamide, chemically known as pyridine-3-carboxylic amide, is considered as the most important component of vitamin B3. It is utilized biologically as an electron carrier for ribose and adenine to constitute coenzymes. In addition, it has significant anti-inflammatory, antimicrobial, and radio-sensitizing activities. ${ }^{1-3}$ Recent studies have reported considerable efficacy of nicotinamide to eradicate both Mycobacterium tuberculosis and AIDS, the two organisms responsible for $35 \%$ of most deaths due to AIDS. ${ }^{4}$ Following oral dosing, nicotinamide is readily absorbed from all portions of the gastrointestinal tract ${ }^{5}$ and metabolized into $N$-methylnicotinamide and nicotinamide
Correspondence: Ahmed S Zidan Department of Pharmaceutics and Industrial Pharmacy, Faculty of Pharmacy, King Abdulaziz University, PO Box 80260, Jeddah 21589, Kingdom of Saudi Arabia

Tel +96656426 6682

Fax+966 I2695 I696

Email aszidan@kau.edu.sa
International Journal of Nanomedicine 20|6: | | |50|-15|6

Dovepress

http://dx.doi.org/10.2147/IJN.SI 02945 (c) (1) (5) 2016 Lidan et al. This work is published and licensed by Dove Medical Press Limited. The full terms of this license are available at https://www.dovepress.com/terms.php C. hereby accept the Terms. Non-commercial uses of the work are permitted without any further permission from Dove Medical Press Limited, provided the work is properly attributed. For permission for commercial use of this work, please see paragraphs 4.2 and 5 of our Terms (https://www.dovepress.com/terms.php). 
$N$-oxide. ${ }^{6}$ It has a short biological half-life of 4 hours with significant fluctuations in its plasma levels and serious adverse actions such as nausea, vomiting, hepatotoxicity, tremor and convulsions, sedation, and coma. ${ }^{7,8}$ Furthermore, a controlled release formulation would be a crucial factor in the effective management of its antimicrobial activity. Hence, nicotinamide supercritical $\mathrm{CO}_{2}$-foamed porous polycaprolactone scaffolds and nanostructured lipid carriers have been developed to improve its therapeutic efficacy. ${ }^{9,10}$ However, the particle growth, unpredictable precipitation tendency, burst release, and drug expulsion limit its practical usefulness. Hence, there is a need for an alternative drug delivery system for nicotinamide to improve its therapeutic efficacy as well as patient compliance.

Recently, polymeric nanoemulsions have shown a considerable interest as a drug delivery system due to their desirable characteristics of vesicular nanosize, improved thermodynamic stability, enhanced solubility of hydrophobic medications, unrecognition by the reticuloendothelial system, controlled release profiles, and long circulation time. ${ }^{11,12}$ Polymeric nanoemulsions encompass a drug-loading core with hydrophilic coating. Amphiphilic block copolymer with its aqueous and organic moieties can form nanoemulsions in aqueous medium through the self-molecular interactions to entrap the hydrophobic medications in the central portion of micelles. ${ }^{13}$ These novel delivery systems have been successfully employed with various medications such as anticancer drugs, ${ }^{14}$ immunosuppressants, ${ }^{11}$ vitamins, ${ }^{15}$ and others to improve their therapeutic efficacy. Eudragit ${ }^{\circledR} \mathrm{S} 100$ is an anionic copolymerization product of methacrylic acid to methyl methacrylate in the ratio of 1:2. It is insoluble in acid but soluble in intestinal medium at $\mathrm{pH} 7$ and thus provides film coats that are resistant to gastric media. ${ }^{16}$ Eudragit S100 has different pharmaceutical applications like formation of enteric coating and controlled release of oral and ophthalmic products. ${ }^{17} 2$-Hydroxypropyl- $\beta$-cyclodextrin $(\mathrm{HP}-\beta-\mathrm{CD})$ is a well-known biocompatible polymer that forms an inclusion complex with insoluble drugs to improve its aqueous solubility and absorption rate. A combination of Eudragit S100 and HP- $\beta-C D$ is proposed in the current study as polymeric nanoemulsions to improve the drug-loading capacity and subsequent therapeutic efficacy of a water-soluble medication.

According to the International Conference on Harmonization Guideline Q8 (R2),

Quality-by-Design (QbD) is a systematic approach to the development that starts with predefined objectives and emphasizes product and process understanding and process control, based on sound science and quality risk management. ${ }^{18}$

QbD mines and understands the effects of input (formulation and process) parameters on the critical quality attributes (CQAs) to constantly manufacture a medicament with the desired quality. ${ }^{19}$ A QbD-based drug product development would comprise a screening design of experiment to define the design space and classify the formulation and process parameters according to their influences on the critical quality parameters. In pharmaceutical industry, $\mathrm{QbD}$ brings cost-efficiency and simplicity of manufacturing process into reality. Several tools are utilized to make QbD system easily applicable in pharmaceutical field, namely design of experiment, risk assessment, and process analytical technology. ${ }^{20}$ The following parameters are defined to describe those characteristics: quality target product profile (QTPP), CQAs, critical material attributes, and critical process parameters. ${ }^{21}$ In this regard, the current study aimed at the preparation and evaluation of a nicotinamide-loaded Eudragit/cyclodextrin nanoemulsion in an attempt to standardize both its clinical efficacy and patient tolerability. Literature search showed scarce information about this investigation up to date. After proposing the QTPP and CQA of target drug product, Plackett-Burman (PB) screening design was employed as a statistically oriented methodology in determining the most influencing formulation and process parameters. It is our hypothesis that QbD-based preparation of nicotinamide in polymeric nanoemulsion might not only extend drug release rate but also sustain its antimicrobial activity, hence reducing the associated adverse effects. To challenge this hypothesis, 12 formulations of nicotinamide-loaded polymeric nanoemulsified particles were prepared using oil-in-water $(\mathrm{O} / \mathrm{W})$ emulsification technique with eight different chemical and physical factors. The formulations were then characterized in terms of encapsulation parameters, vesicular size (z-average) and size distribution, surface charge intensity, and drug release within 24 hours.

\section{Materials and methods Materials}

Nicotinamide was supplied from BDH Laboratories (Poole, UK). Eudragit S100 was purchased from Evonik Industries AG (Essen, Germany). HP- $\beta$-CD (average molecular weight of 1,380 mol/L) was purchased from ABCR GmbH (Karlsruhe, Germany). Analytical-grade methanol was purchased from VWR International (Radnor, PA, USA). Magnesium chloride $\left(\mathrm{MgCl}_{2}\right)$ was purchased from Sigma-Aldrich Co. (St Louis, MO, USA). Other reagents and chemicals were 
of analytical reagent grade. All experiments were carried out using ultrapure water.

\section{Chromatographic analysis for the determination of nicotinamide}

Nicotinamide was assayed in samples during different experimentations using the method reported by Revelli et al with some modifications. ${ }^{22}$ HP-chromatographic system (Agilent Technologies, Santa Clara, CA, USA) consisted of $1200 \mathrm{HP}-\mathrm{UV}$ detector set at $265 \mathrm{~nm}$, identified through UV spectral scan of 200-400 $\mathrm{nm}$ range, HP-1200 automatic sampling compartment, and four-array pump. The column temperature was adjusted at $30^{\circ} \mathrm{C}$. The chromatographic elution was done by injecting $20 \mu \mathrm{L}$ samples onto Luna reversed phase ODS $(250 \times 4.6 \mathrm{~mm}, 5 \mu \mathrm{m}$ particle diameter $)$ chromatographic column protected with ODS $(4.0 \times 2.0 \mathrm{~mm})$ guard column (Phenomenex Ltd., Torrance, CA, USA). The eluting medium was acetonitrile-phosphate buffer ( $\mathrm{pH} 3.3$, $10 \mathrm{mM}$ ) at 70:30 volume ratio and was pumped isocratically at a rate $1.25 \mathrm{~mL} / \mathrm{min}$.

\section{Polymeric nanoemulsions preparation}

A nicotinamide-entrapped polymeric nanoemulsion was prepared using $\mathrm{O} / \mathrm{W}$ emulsification technique followed by organic phase evaporation. The specified amounts of nicotinamide (20 or $40 \mathrm{mg}$ ) and Eudragit S100 (100 or $200 \mathrm{mg}$ ) were dissolved in a specified volume of methanol (15 or $30 \mathrm{~mL}$ ) according to the formulae listed in Table 1. The resultant organic phase was added dropwise to a specified volume ( 40 or $80 \mathrm{~mL}$ ) of an aqueous solution of HP- $\beta-C D$ (100 or $200 \mathrm{mg}$ ) under mechanical agitation at $800 \mathrm{rpm}$ and continual homogenization using a probe homogenizer at
6,000 rpm and clearance of $0.1-0.2 \mathrm{~mm}$ (Probe-homogenizer, PowerGen 125; Thermo Fisher Scientific, Waltham, MA, USA) until complete emulsification and then organic phase evaporation. Magnesium chloride was added as a stabilizer at either $0.05 \%$ or $0.1 \%(\mathrm{v} / \mathrm{v})$ to the produced nanoemulsion, and the system was comminuted using an ultrasound probe at $30^{\circ} \mathrm{C}$ for a specified time (90 or 180 seconds) and amplitude (30\% or $60 \%)$ in ON/OFF cycles. The obtained dispersion was then stirred overnight at ambient temperature to rigidize the polymer over the formed nicotinamide-loaded nanoparticles. Excess un-entrapped nicotinamide was removed by centrifugation at $85,000 \mathrm{rpm}$ for 2 hours. The resultant residue was reconstituted with $2 \mathrm{~mL}$ of phosphate buffer ( $\mathrm{pH} 3.3,10 \mathrm{mM})$ for the lyophilization process. For this purpose, the reconstituted residue was frozen at $-70^{\circ} \mathrm{C}$ and then dried in open tray freeze-drying System (Labconco Corp., Kansas City, MO, USA) at $-30^{\circ} \mathrm{C}$ for 48 hours. The dried polymeric nanoemulsified particles were then stored in fridge until further study.

\section{PB screening design}

A set of experiments using PB experimental design was adopted in the current study to prepare nicotinamide-loaded polymeric nanoemulsions. Twelve runs at different levels of eight independent factors were designed using JMP-software (JMP version 11; SAS Institute Inc., Cary, NC, USA). The formulation and process variables were Eudragit S100, HP- $\beta-C D$, nicotinamide, and magnesium chloride loadings, volumes of methanol (organic phase) and phosphate buffer of $\mathrm{pH} 3.3$ (aqueous phase), and ultrasonication time and amplitude. On the other hand, the investigated responses were encapsulation parameters, vesicular size ( $z$-average) and size

Table I Composition and processing variables of different nicotinamide-loaded polymeric nanoemulsified particles according to Plackett-Burman screening design

\begin{tabular}{|c|c|c|c|c|c|c|c|c|}
\hline \multirow[t]{2}{*}{ Batch \# } & \multirow{2}{*}{$\begin{array}{l}\text { Eudragit } \\
\text { SIO0 (mg) } \\
X I\end{array}$} & \multirow{2}{*}{$\begin{array}{l}\mathrm{HP}-\beta-C D \\
(\mathrm{mg}) \\
\mathrm{X} 2\end{array}$} & \multirow{2}{*}{$\begin{array}{l}\text { Drug loading } \\
\text { (mg) } \\
\times 3\end{array}$} & \multirow{2}{*}{$\begin{array}{l}\text { Organic } \\
\text { volume }(\mathrm{mL}) \\
\mathrm{X4}\end{array}$} & \multirow{2}{*}{$\begin{array}{l}\text { Aqueous } \\
\text { volume }(\mathrm{mL}) \\
\mathrm{X5}\end{array}$} & \multirow{2}{*}{$\begin{array}{l}\text { Ultrasonication } \\
\text { time (s) } \\
\text { X6 }\end{array}$} & \multirow{2}{*}{$\begin{array}{l}\text { Ultrasonication } \\
\text { amplitude (\%) } \\
\text { X7 }\end{array}$} & \multirow{2}{*}{$\begin{array}{l}\mathrm{MgCl}_{2} \text { stabilizer } \\
\text { level (\%) } \\
\times 8\end{array}$} \\
\hline & & & & & & & & \\
\hline $\mathrm{FI}$ & 200 & 200 & 40 & 15 & 80 & 180 & 30 & 0.1 \\
\hline $\mathrm{F} 2$ & 100 & 100 & 20 & 30 & 80 & 180 & 30 & 0.1 \\
\hline F3 & 200 & 200 & 20 & 30 & 80 & 90 & 60 & 0.05 \\
\hline $\mathrm{F} 4$ & 100 & 200 & 20 & 15 & 40 & 180 & 60 & 0.1 \\
\hline F5 & 200 & 100 & 20 & 15 & 80 & 180 & 60 & 0.05 \\
\hline F6 & 100 & 200 & 40 & 15 & 80 & 90 & 30 & 0.05 \\
\hline F7 & 200 & 200 & 20 & 30 & 40 & 90 & 30 & 0.1 \\
\hline F8 & 100 & 100 & 20 & 15 & 40 & 90 & 30 & 0.05 \\
\hline F9 & 200 & 100 & 40 & 30 & 40 & 180 & 30 & 0.05 \\
\hline FIO & 100 & 200 & 40 & 30 & 40 & 180 & 60 & 0.05 \\
\hline FII & 100 & 100 & 40 & 30 & 80 & 90 & 60 & 0.1 \\
\hline $\mathrm{FI} 2$ & 200 & 100 & 40 & 15 & 40 & 90 & 60 & 0.1 \\
\hline
\end{tabular}

Abbreviation: HP- $\beta-C D$, 2-hydroxypropyl- $\beta$-cyclodextrin. 
distribution (polydispersity index [PDI]), surface charge (zeta potential), and drug release within 24 hours.

\section{Characterization of nicotinamide-loaded polymeric nanoemulsions}

After harvesting the prepared vesicles by centrifugation, the free drug in the supernatant was assessed for the indirect estimation of the vesicles' capacity to entrap nicotinamide. The entrapment efficiency (EE) will then be calculated using the following equation, where $A_{\mathrm{t}}$ is the total amount of nicotinamide dissolved in the organic phase and $A_{\mathrm{m}}$ equals ( $A_{\mathrm{t}}-$ drug content in supernatant):

$$
\mathrm{EE} \%=\frac{A_{\mathrm{m}} \times 100}{A_{\mathrm{t}}}
$$

On the other hand, the direct estimation of drug load within the polymeric nanovesicles (entrapment capacity [EC]) was done by dissolving the lyophilized powder in methanol followed by quantitation using the developed high-performance liquid chromatographic method after appropriate dilutions.

Vesicular size parameter and electrophoretic properties were determined using laser diffraction technique (2000 SM; Malvern Instruments, Malvern, UK) at a temperature of $25^{\circ} \mathrm{C}$. The morphology of the prepared polymeric nanoemulsified vesicles was investigated using transmission electron microscopy. For image capturing, the nanoemulsified dispersion was added to copper grid precoated with carbon, followed by air drying and staining with $2 \%$ phosphotungstic acid.

Solid-state analysis of the lyophilized powder was performed with differential scanning calorimetry (DSC), X-ray diffraction (XRD), and Fourier transform infrared spectroscopy (FTIR) analysis. DSC thermograms were recorded using a Shimadzu DSC system (Shimadzu Co., Kyoto, Japan). For this purpose, $1.5 \mathrm{mg}$ samples was packed in aluminum pans, tightly sealed using a special piston, and then heated over the temperature range of $30^{\circ} \mathrm{C}-300^{\circ} \mathrm{C}$ at a ramping rate of $10^{\circ} \mathrm{C} / \mathrm{min}$ under an atmosphere of nitrogen pumped continuously at a rate of $30 \mathrm{~mL} / \mathrm{min}$. XRD diffractograms were recorded using powder diffractometer (Kristallofex D-5000 powder diffractometer; Siemens AG Co., Munich, Germany) at a scanning step of $8^{\circ} / \mathrm{min}$ with a $2 \theta$ range of $0^{\circ}-80^{\circ}$. FTIR spectra were collected using FTIR spectrophotometer (1600 series; PerkinElmer Corporation, Waltham, MA, USA) using $\mathrm{KBr}$ disk method. The scanning range started from 600 up to $4,000 \mathrm{~cm}^{-1}$ at $1 \mathrm{~cm}^{-1}$ resolution step.
In vitro nicotinamide release from the prepared systems was studied using dialysis Float-A-Lyzer tubes (18 kDa cellulose ester membrane). The release experiments were performed in acidic media ( $\mathrm{pH} 3.3$ ) to maintain the sink condition. A corresponding volume of the dispersion in phosphate buffer $(\mathrm{pH} 3.3$, $10 \mathrm{mM}$ ) equivalent to $300 \mu \mathrm{g}$ nicotinamide was inserted into the dialysis tubes. The tubes were then immersed in $50 \mathrm{~mL}$ of the same buffer system. The entire assembly was kept under continual agitation $(120 \mathrm{rpm})$ at $37^{\circ} \mathrm{C}$. At a specified time interval, aliquots were removed from the external media and replaced with fresh medium of equal volume in order to preserve sink condition. The collected samples were assessed for nicotinamide release using the developed high-performance liquid chromatographic method. The amount of the drug released in 24 hours was used for the comparison and model fitting.

\section{Antibacterial screening test}

The in vitro antimicrobial screening of nicotinamide raw material and its polymeric nanoemulsions was performed against the bacterial scrums such as Bacillus subtilis, Staphylococcus aureus, Escherichia coli, and Pseudomonas aeruginosa, and their efficiency against the bacteria was compared with the standard chloramphenicol by the disk diffusion method. ${ }^{23}$ For this purpose, the tested bacteria were cultured in Mueller Hinton broth at $37^{\circ} \mathrm{C}$ overnight with shaking (200 rpm). A sample of each culture was then diluted 40-fold in fresh blood-heart infusion agar and incubated at $37^{\circ} \mathrm{C}$ for $2-3$ hours. An aliquot of either 100 or $200 \mu \mathrm{g} / \mathrm{mL}$ nicotinamide-equivalent polymeric nanoemulsified particles dispersed in dimethyl sulfoxide (DMSO) was applied on a sterilized cellulose disk $(6 \mathrm{~mm})$ placed on a blood-heart infusion agar plates $(0.8 \%, \mathrm{w} / \mathrm{v})$ inoculated with each pathogen (112 cfu/mL). Plates were incubated at $37^{\circ} \mathrm{C}$ for 24 hours, and the diameters of the inhibition zones around the disks were measured. Minimum inhibitory concentrations (MICs) were determined visually, being defined as the lowest concentration showing no visible growth. Since DMSO was used as a solvent for nicotinamide as well as a dispersant for the polymeric nanoemulsions, it was also screened against the organisms as a negative control. Vancomycin, daptomycin, and gentamcin were used as positive inhibitor controls. Experiments were performed in duplicates.

\section{Results and discussion QbD approach for development of polymeric nanoemulsified particles}

Polymeric nanoemulsified particles were prepared by $\mathrm{O} / \mathrm{W}$ emulsification technique followed by organic phase 
A
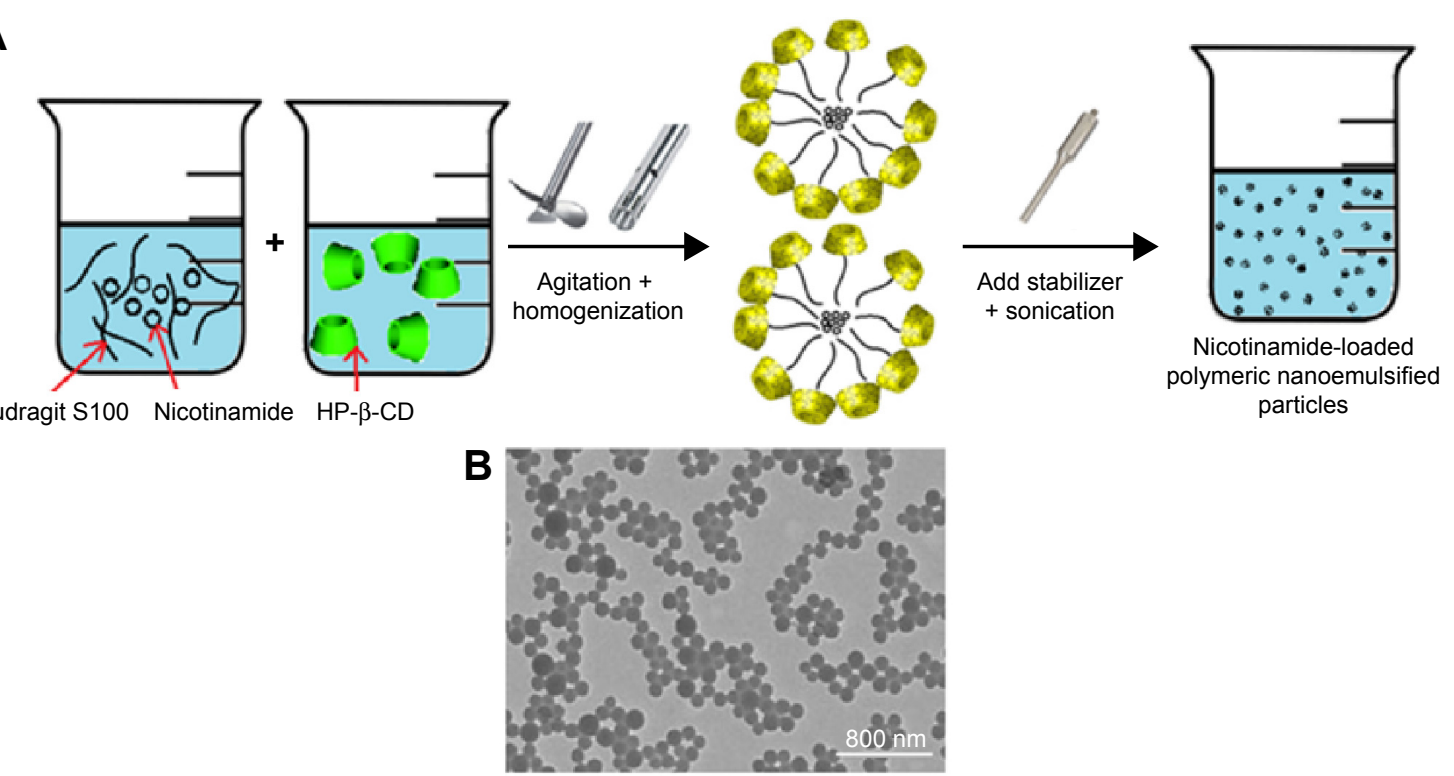

Figure I Preparation technique and TEM image of nicotinamide-loaded polymeric nanoemulsified particles.

Notes: Schematic development representation (A) and batch 7 TEM image (B) of nicotinamide-loaded polymeric nanoemulsified particles. Abbreviations: TEM, transmission electron microscopy; HP- $\beta$-CD, 2-hydroxypropyl- $\beta$-cyclodextrin.

evaporation as described in Figure 1A. Transmission electron microscopy micrographs indicated that prepared nanoparticles were characterized with spherical micelles and self-organized aggregates (Figure 1B). The aim of this work was using $\mathrm{QbD}$ approach to develop polymeric nanoemulsified particles with potential to be incorporated into a liquid or semisolid (gel) dosage form, for implantation. Hence, the pharmaceutical development started with defining the QTPP of a low-viscosity aqueous suspension or gel with polymeric nanoemulsified particles for injection. A defined yet justified QTPP (Table 2) was used to lead the pharmaceutical development process of the proposed product that should be pharmaceutically equivalent with reference-listed drug product. Quality attributes for target drug product are presented in Table 2, and CQAs are appropriately marked and justified. Usually, quality risk management analysis is done on the basis of available literature and/or historical data. Considering that literature data in form of original scientific research publications related to the polymeric nanoemulsified particles are limited, our approach to quality risk management combined literature reference data and results derived from multivariate statistical analysis (principle component analysis [PCA] and partial least square regression) performed on experimental data of the PB design. PCA unscrambles $\mathrm{X}$ variables matrix into number of latent variables called principal components (PCs). PCA applied on the experimental data presented in Table 3 resulted with one $\mathrm{PC}$ that maximizes the explained variance in the data set. The PCA model with one PC (PC1) explains $92.8 \%$ of the variation in the data set (X). The parameter $Q^{2}$ obtained with cross-validation of the model has a value of $63.9 \%$, and it refers to the percentage of variation of all $\mathrm{X}$ variables that can be estimated with the model. Values of $Q^{2}>50 \%$ would indicate a good predictability; hence, the model is acceptable, and it was used for identification of formulation and process parameters influencing polymeric nanoemulsified particles formation. Score scatter plot is a useful tool to indicate any pattern in the results (eg, clusters, trends, or outliers). Score scatter plot of performed PC X-Y analyses (Figure 2) clearly points to no clusters to be observed for the effects of the independent variables on the resultant EC, particle size, PDI, and zeta potential. On the other hand, two clusters were observed for the effect of independent variables on both EE and drug release. For EE, group 1 was closely related with volumes of aqueous and organic phases and drug level, while group 2 was correlated with Eudragit and HP- $\beta$-CD levels. For drug release response, group 1 was closely related with aqueous phase volume, sonication time, and HP- $\beta$-CD level, while group 2 was correlated with organic phase volume, sonication amplitude, and $\mathrm{MgCl}_{2}$ level. This PCA revealed the similarities and origin of differences between the samples and analysis. However, it should be noted that PCA could not detect whether the observed differences will affect the manufacturing process and product quality; ${ }^{24}$ therefore, subsequent analyses as well as sufficient process and 
Table 2 QTPP and CQA of target drug product, gel with polymeric nanoemulsified particles, for injection

\begin{tabular}{|c|c|c|}
\hline \multicolumn{3}{|c|}{ QTPP of a gel with polymeric nanoemulsified particles } \\
\hline QTPP elements & Target & Justification \\
\hline Dosage form & Hydrogel & $\begin{array}{l}\text { Pharmaceutical equivalence requirement: same } \\
\text { dosage form }\end{array}$ \\
\hline Route of administration & Injection & $\begin{array}{l}\text { Pharmaceutical equivalence requirement: same } \\
\text { route of administration }\end{array}$ \\
\hline Dosage strength & $\%$ of drug substance $(\% \mathrm{w} / \mathrm{w})$ & $\begin{array}{l}\text { Pharmaceutical equivalence requirement: same } \\
\text { dosage strength }\end{array}$ \\
\hline Dosage form design & $\begin{array}{l}\text { Polymeric nanoemulsified carriers incorporated } \\
\text { into hydrogel }\end{array}$ & Match reference-listed drug product \\
\hline Pharmacokinetics & Bioequivalent to reference-listed drug & Match reference-listed drug product \\
\hline Stability & Shelf life not $<24$ months at room temperature & $\begin{array}{l}\text { Equivalent or longer shelf life compared to } \\
\text { reference-listed drug product }\end{array}$ \\
\hline Drug product quality attributes & $\begin{array}{l}\text { Physical attributes, identification, assay, } \\
\text { uniformity of content, degradation products, } \\
\text { residual solvents, dissolution, microbiological }\end{array}$ & $\begin{array}{l}\text { Pharmaceutical equivalence requirement: fulfill the } \\
\text { same quality standards as reference-listed drug } \\
\text { product }\end{array}$ \\
\hline
\end{tabular}

Container closure system quality, $\mathrm{pH}$, and rheological behavior Suitable container closure system that will support estimated shelf life and drug product integrity during the transport, Identical primary

Vials or prefilled syringes, similar with referencelisted drug product, acceptable for the patient packaging as reference-listed drug product

\begin{tabular}{|c|c|c|c|}
\hline \multirow{2}{*}{\multicolumn{4}{|c|}{$\begin{array}{l}\text { Alternative methods of administration } \quad \text { No } \\
\text { CQAs of gel with polymeric nanoemulsified particles }\end{array}$}} \\
\hline & & & \\
\hline Drug product quality attributes & Target & Is it a CQA? & Justification \\
\hline Appearance & $\begin{array}{l}\text { Color and shape acceptable } \\
\text { for the patient }\end{array}$ & No & $\begin{array}{l}\text { Color and shape are not directly related to the safety and } \\
\text { efficacy. Required for patient acceptability }\end{array}$ \\
\hline $\begin{array}{l}\text { Particle size and particle size } \\
\text { distribution }\end{array}$ & $\begin{array}{l}\text { Similar to reference-listed } \\
\text { drug }\end{array}$ & Yes & $\begin{array}{l}\text { It might influence drug entrapment efficacy and capacity, as well } \\
\text { as drug release. It is critical for drug product efficacy and safety }\end{array}$ \\
\hline Rheological behavior & $\begin{array}{l}\text { Conform to Ph. Eur. } \\
\text { 7.0-2.2.10 }\end{array}$ & Yes & $\begin{array}{l}\text { Required to demonstrate Q3 (same components in same } \\
\text { concentrations with same microstructure) }\end{array}$ \\
\hline $\mathrm{pH}$ & $\begin{array}{l}\text { Conform to Ph. Eur. } \\
7.0-2.2 .3\end{array}$ & Yes & $\begin{array}{l}\text { Might influence drug product stability and hence its efficacy } \\
\text { and safety. This CQA can be effectively controlled by quality } \\
\text { management system }\end{array}$ \\
\hline Identification & Positive for drug substance & Yes & $\begin{array}{l}\text { Identification is critical for safety and efficacy, but this CQA can } \\
\text { be efficiently controlled by quality management system and will } \\
\text { be followed during dissolution studies. Formulation and process } \\
\text { variables cannot influence identity }\end{array}$ \\
\hline Assay & $90 \%-110 \%$ of label claim & Yes & Assay variability will have influence upon safety and efficacy \\
\hline Content uniformity & Conform to USP $<3>$ & Yes & $\begin{array}{l}\text { Variability in content homogeneity and uniformity of content will } \\
\text { affect safety and efficacy }\end{array}$ \\
\hline Residual solvents & Conform to ICH Q3C (R5) & Yes & $\begin{array}{l}\text { Polymeric nanoemulsified particles manufacturing procedure } \\
\text { includes use of methanol. Its residual quantity is critical for safety }\end{array}$ \\
\hline Degradation products & Conform to ICH Q3B (R2) & Yes & $\begin{array}{l}\text { Degradation products limit is critical for safety. Limit of individua } \\
\text { unknown degradation products must comply with ICH Q3B (R2) } \\
\text { Limit of total degradation products is based on reference-listed } \\
\text { drug product analysis near the expiry date }\end{array}$ \\
\hline In vitro dissolution profile & $\begin{array}{l}\text { Match reference-listed drug } \\
\text { product }\end{array}$ & Yes & $\begin{array}{l}\text { As the in vitro drug release is surrogate for in vivo performance, } \\
\text { the target is to ensure similar dissolution profile compared to } \\
\text { reference-listed drug product }(f 2>50)\end{array}$ \\
\hline Microbiological quality & $\begin{array}{l}\text { Conform to } \mathrm{Ph} \text {. Eur. } \\
7.0-5.1 .4\end{array}$ & Yes & $\begin{array}{l}\text { Noncompliance of microbiological quality will have impact upon } \\
\text { safety }\end{array}$ \\
\hline Efficacy of antimicrobial preservation & $\begin{array}{l}\text { Conform to Ph. Eur. } \\
7.0-5.1 .3\end{array}$ & Yes & $\begin{array}{l}\text { Inefficiency of the preservative at declared storage conditions } \\
\text { might result in microbiological contamination and affect safety }\end{array}$ \\
\hline Container closure system & $\begin{array}{l}\text { Similar to reference-listed } \\
\text { drug }\end{array}$ & No & $\begin{array}{l}\text { Match reference-listed drug product. Required for patient } \\
\text { acceptability }\end{array}$ \\
\hline Packaging integrity & No failure & No & Required for stability, efficacy, and safety \\
\hline
\end{tabular}

Note: Q3, the US Food and Drug Administration similarity definition of the generic drug had the same components in the same concentration with the same arrangement of matter (microstructure) as the reference-listed drug.

Abbreviations: QTPP, quality target product profile; CQAs, critical quality attributes; Ph. Eur., European Pharmacopoeia; USP, United States Pharmacopeia; ICH, International Conference on Harmonization guidelines. 
Table 3 Characterization of the prepared nicotinamide-loaded polymeric nanoemulsified particles

\begin{tabular}{|c|c|c|c|c|c|c|c|}
\hline Batch \# & $\begin{array}{l}\text { Entrapment } \\
\text { capacity (\%) }\end{array}$ & $\begin{array}{l}\text { Entrapment } \\
\text { efficiency (\%) }\end{array}$ & $\begin{array}{l}\text { Particle } \\
\text { size }(\mathrm{nm})\end{array}$ & PDI & $\begin{array}{l}\text { Zeta potential } \\
(\mathrm{mV})\end{array}$ & $\begin{array}{l}\% \text { of drug released } \\
\text { in } 24 \text { hours }\end{array}$ & Charge \\
\hline $\mathrm{FI}$ & 61.23 & 61.77 & 185.7 & 0.25 & 35.3 & 16.6 & Negative \\
\hline F2 & 34.38 & 55.74 & 43.3 & 0.08 & 20.6 & 15 & Negative \\
\hline F3 & 68.86 & 57.42 & 196.7 & 0.1 & 38.9 & 5.8 & Negative \\
\hline $\mathrm{F} 4$ & 63.36 & 60.42 & 89.3 & 0.08 & 41.9 & 10.1 & Negative \\
\hline F5 & 33.52 & 59.84 & 231 & 0.18 & 53.3 & 7.7 & Negative \\
\hline F6 & 78.84 & 57.96 & 160.3 & 0.15 & 12.4 & 18.6 & Negative \\
\hline F7 & 67.44 & 67.11 & 202 & 0.17 & 36.7 & 19.8 & Negative \\
\hline F8 & 65.92 & 64.96 & 87 & 0.15 & 38.3 & 22.4 & Negative \\
\hline F9 & 36.64 & 63.68 & 183.3 & 0.09 & 39.4 & 13.4 & Negative \\
\hline FIO & 59.84 & 55.02 & 160.3 & 0.19 & 16.1 & 6.5 & Negative \\
\hline FII & 47.84 & 53.12 & 243.3 & 0.19 & 9.5 & 9.6 & Negative \\
\hline $\mathrm{FI} 2$ & 38.64 & 61.94 & 434 & 0.28 & 36.2 & 19.2 & Negative \\
\hline
\end{tabular}

Note: Relative standard deviations did not exceed $5 \%$ of the stated responses' values.

Abbreviation: PDI, polydispersity index.

product knowledge and understanding are required. After identification of the variables associated with two groups of results, the next step was to determine how $\mathrm{X}$ variables influence the investigated characteristics of the polymeric nanoemulsified particles. For this reason, multiple regression analysis was applied to the experimental results associated with particles formation (total of 12 samples; Tables 3 and 4).

\section{Nicotinamide EC and EE}

Table 3 shows that nicotinamide EC and EE ranged from $33.52 \%$ (F5) to $68.86 \%$ (F3) and from $53.15 \%$ (F11) to $67.11 \%$ (F7), respectively, for different factors involved in the preparation of the polymeric nanoemulsified particles. Quantile-quantile plot showed a linear relationship between the observed and predicted EC and EE percentages. The coefficients of multiple determination $\left(R^{2}\right)$ values were 0.9630 and 0.9777 (Table 4) which demonstrate the accuracy and robustness of the obtained regression models. Subsequent analysis of variance (ANOVA) showed a significant effect of the formulation and process variables on the measured EC and EE percentages with Prob $>F$ values of 0.0436 and 0.0277 at $P<0.05$, respectively (Table 4 ). The overall reduced prediction equation to relate the individual effects of only the significant factors on nicotinamide EC and EE percentage is shown as follows:

$$
\begin{aligned}
\underset{\text { EC }}{\text { Nicotinamide }}= & 54.7+11.8 *\left(\frac{(\mathrm{HP}-\beta-\mathrm{CD}(\mathrm{mg})-150)}{50}\right) \\
& -6.5^{*}\left(\frac{(\text { Ultrasonication time }(\mathrm{s})-135)}{45}\right)
\end{aligned}
$$

$$
\begin{aligned}
\text { Nicotinamide }= & 59.9+2.04 *\left(\frac{(\text { Eudragit S100 }(\mathrm{mg})-150)}{50}\right) \\
& -1.2^{*}\left(\frac{(\text { Organic volume }(\mathrm{mL})-22.5)}{7.5}\right) \\
& -2.2^{*}\left(\frac{(\text { Aqueous volume }(\mathrm{mL})-60)}{20}\right) \\
& -1.9^{*}\left(\frac{(\text { Ultrasonication amplitude }(\%)-45)}{15}\right)
\end{aligned}
$$

Out of three formulation variables, two factors were significant for their effects on EC and EE, namely HP- $\beta$-CD and Eudragit loading concentrations. On the other hand, ultrasonic parameters and volume of aqueous and organic phases were the significant processing parameters in both responses. As shown in Table 4 and Figure 3, HP- $\beta$-CD level showed the highest significant effect on the resultant EC ( $P=0.0057)$ followed by ultrasonic time $(P=0.0294)$. On the other hand, volume of the organic phase was the most important factor that controlled nicotinamide EE followed by Eudragit concentration and ultrasonic amplitude. Positive relationships were observed by increasing both HP- $\beta-C D$ and Eudragit loading concentrations (Figure 4), with maximum $\mathrm{EC}$ and $\mathrm{EE}$ of $68 \%$ and $67 \%$, respectively, occurring at approximately $200 \mathrm{mg}$ HP- $\beta-\mathrm{CD}$ and $200 \mathrm{mg}$ Eudragit S100 experimental loadings. On the other hand, a negative curvature was observed (Figure 4) by increasing ultrasonic time and amplitude with minimum EC and EE of $33 \%$ and $53 \%$, respectively, obtained under ultrasonic time and amplitude of 180 seconds and $60 \%$, respectively. The marked positive effect of HP- $\beta-C D$ on EC can be described by the structural configuration of the branched copolymer, HP- $\beta-C D$, which encompasses a cyclic oligosaccharide with 

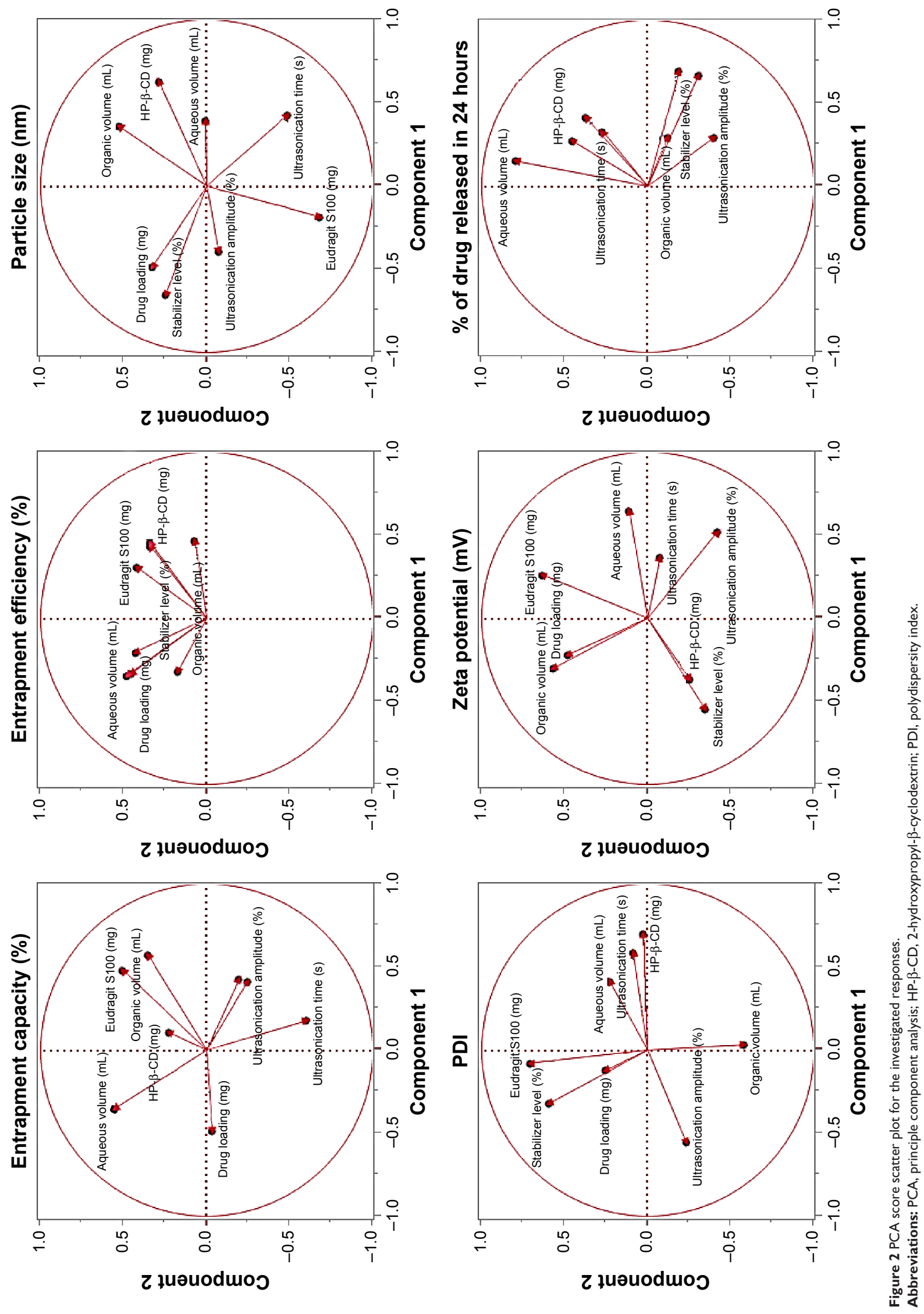
Table 4 Results of multiple regression and ANOVA for prediction of the investigated responses

\begin{tabular}{|c|c|c|c|c|c|c|}
\hline Factors $^{\mathrm{a}}$ & $\begin{array}{l}\text { Entrapment } \\
\text { capacity (\%) }\end{array}$ & $\begin{array}{l}\text { Entrapment } \\
\text { efficiency (\%) }\end{array}$ & $\begin{array}{l}\text { Particle } \\
\text { size }(\mathrm{nm})\end{array}$ & PDI & $\begin{array}{l}\text { Zeta potential } \\
(\mathrm{mV})\end{array}$ & $\begin{array}{l}\% \text { of drug released } \\
\text { in } 24 \text { hours }\end{array}$ \\
\hline \multicolumn{6}{|l|}{$\mathrm{XI}$} & 13.725 \\
\hline Estimate & -3.65 & 2.05 & 54.10 & 0.019 & 8.417 & -0.025 \\
\hline$P$-value & 0.1161 & 0.0129 & 0.0196 & 0.4332 & 0.0092 & 0.9650 \\
\hline \multicolumn{7}{|l|}{$\times 2$} \\
\hline Estimate & 11.89 & 0.04 & -18.97 & -0.003 & -1.333 & -0.825 \\
\hline$P$-value & 0.0057 & 0.9331 & 0.2068 & 0.9137 & 0.4107 & 0.2142 \\
\hline \multicolumn{7}{|l|}{$\times 3$} \\
\hline Estimate & -0.87 & -1.00 & 43.13 & 0.033 & -6.733 & 0.258 \\
\hline$P$-value & 0.6376 & 0.0801 & 0.0355 & 0.2233 & 0.0171 & 0.6565 \\
\hline \multicolumn{7}{|l|}{$\times 4$} \\
\hline Estimate & -2.21 & -1.23 & -13.20 & -0.023 & -4.683 & -2.042 \\
\hline$P$-value & 0.2771 & 0.0489 & 0.3454 & 0.3670 & $0.044 \mid$ & 0.0302 \\
\hline \multicolumn{7}{|l|}{$\times 5$} \\
\hline Estimate & -0.60 & -2.27 & -7.97 & -0.001 & -3.217 & -1.508 \\
\hline$P$-value & 0.7439 & 0.0096 & 0.5485 & 0.9712 & 0.1050 & 0.0639 \\
\hline \multicolumn{7}{|l|}{$\times 6$} \\
\hline Estimate & -6.55 & -0.50 & -35.87 & -0.014 & 2.883 & -2.175 \\
\hline$P$-value & 0.0294 & 0.2813 & 0.0561 & 0.5523 & 0.1313 & 0.0256 \\
\hline \multicolumn{7}{|l|}{$\times 7$} \\
\hline Estimate & -2.70 & -1.96 & -41.08 & 0.011 & 1.100 & -3.908 \\
\hline$P$-value & 0.2040 & 0.0147 & 0.0402 & 0.6450 & 0.4889 & 0.0050 \\
\hline \multicolumn{7}{|l|}{ X8 } \\
\hline Estimate & -2.56 & 0.10 & -14.92 & 0.016 & -1.517 & 1.325 \\
\hline$P$-value & 0.2222 & 0.8084 & 0.2961 & 0.5099 & 0.3575 & 0.0860 \\
\hline \multicolumn{7}{|c|}{ Analysis of variance } \\
\hline DF & 8 & 8 & 8 & 8 & 8 & 8 \\
\hline SS & $2,608.02$ & 191.50 & $102,978.02$ & 0.030 & I,944.723 & 347.433 \\
\hline MS & 326.00 & 23.94 & | 2,872.30 & 0.004 & 243.090 & 43.429 \\
\hline F-ratio & 9.77 & 13.52 & 7.68 & 0.695 & 10.358 & 13.122 \\
\hline Prob $>F$ & 0.0436 & 0.0277 & 0.0406 & 0.6982 & 0.0402 & 0.0289 \\
\hline$R^{2}$ & 0.9630 & 0.9777 & 0.9534 & 0.6495 & 0.9650 & 0.9722 \\
\hline
\end{tabular}

Notes: Bold values reflect significant factors that affect the corresponding response. ${ }^{a} \mathrm{XI}-\mathrm{X} 8$ are Eudragit SI00, HP- $\beta-\mathrm{CD}$, and drug loadings (mg), volumes of organic and aqueous phases (mL), ultrasonication time (s) and amplitude (\%), and level of $\mathrm{MgCl}_{2}$ as a stabilizer (\%), respectively.

Abbreviations: ANOVA, analysis of variance; PDI, polydispersity index; DF, degree of freedom; SS, sum of squares; MS, mean of squares; F-ratio, model mean square divided by error mean square; Prob $>F$ value, probability of obtaining an $F$-ratio as large as what is observed; $R^{2}$, coefficient of multiple determination for predicted versus measured values.

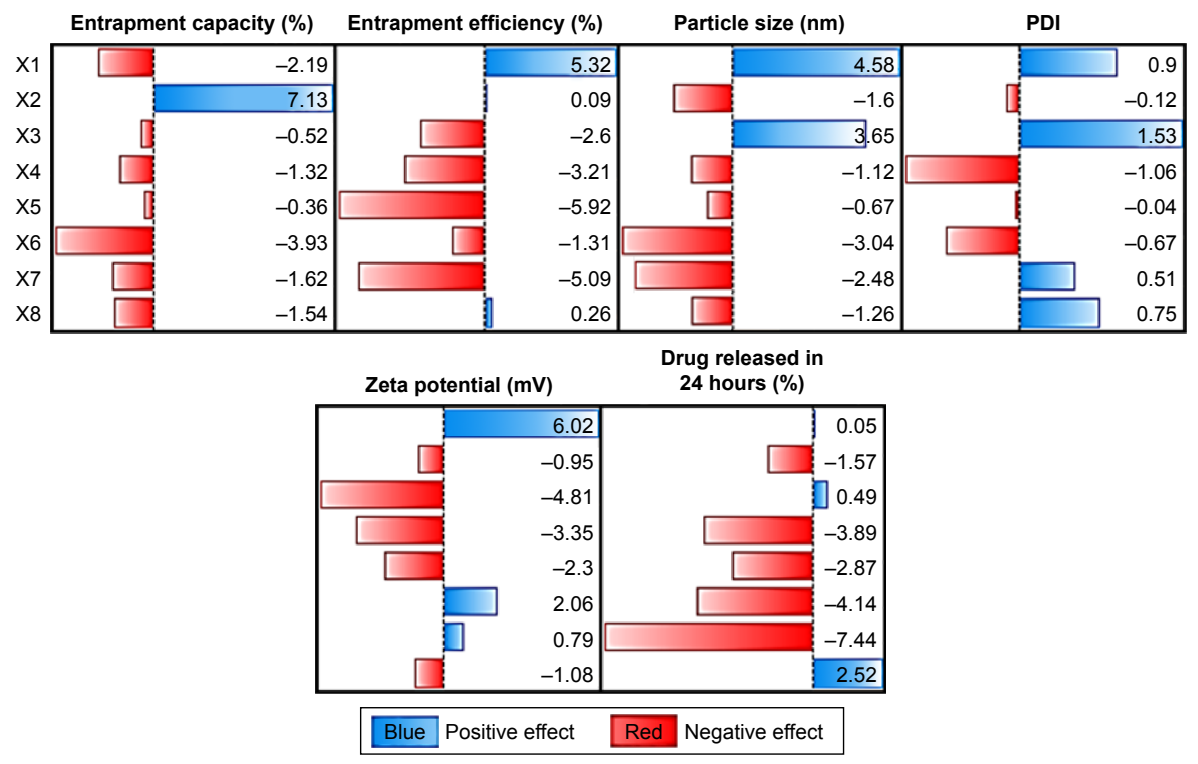

Figure 3 Pareto charts of the main effects of variables on the investigated responses.

Notes: XI-X8 are Eudragit SI00, HP- $\beta-C D$ and drug loadings (mg), volumes of organic and aqueous phases (mL), ultrasonication time (s) and amplitude (\%), and level of $\mathrm{MgCl}_{2}$ as a stabilizer (\%), respectively.

Abbreviations: HP- $\beta$-CD, 2-hydroxypropyl- $\beta$-cyclodextrin; PDI, polydispersity index. 

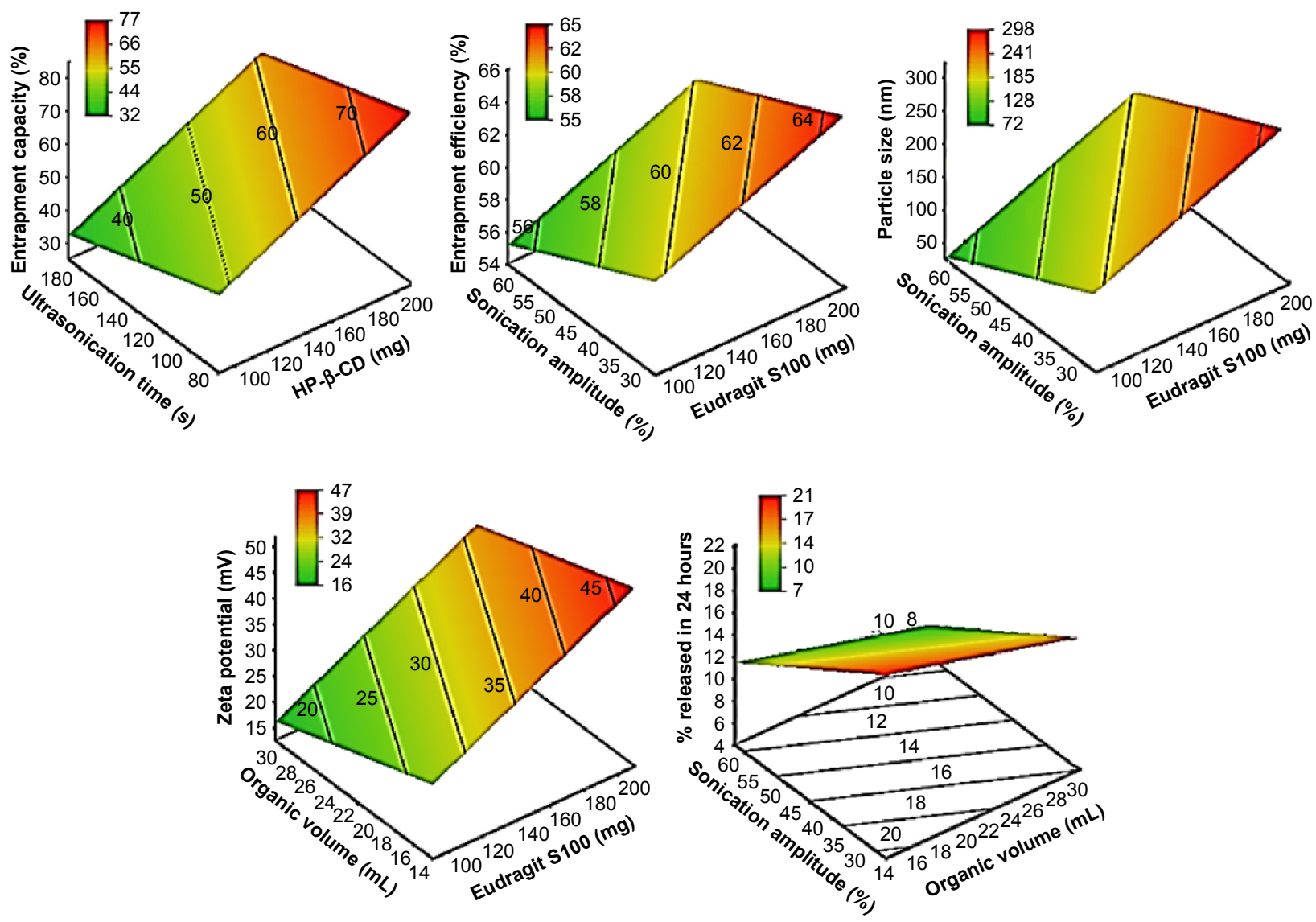

Figure 4 Response surface plots for predicting the characteristics of the prepared polymeric nanoemulsified particles with respect to changing the independent variables. Abbreviation: HP- $\beta-C D, 2$-hydroxypropyl- $\beta$-cyclodextrin.

seven D-glucose moieties linked by an $\alpha$-1,4-glucosidic bond. This structure would provide a rigid configuration in which the primary $-\mathrm{OH}$ groups are oriented toward the narrow side and the secondary $-\mathrm{OH}$ groups are on the wide side of the torus. Having this configuration, HP- $\beta-C D$ would form a hydrophilic outer surface and hydrophobic inner cavity to entrap whole or part of drug molecules, hence providing a molecular shield with minimal leakage through inner cavity. ${ }^{25,26}$ The negative effect of the organic phase volume of EE would be ascribed by decreasing the viscosity of the internal phase. This would facilitate the shearing action to leach out drug molecules out of the formed matrix. The negative effects of the ultrasonication parameters on both EC and EE might be explained by the drug leakage and precipitation as the formulation was subjected to long ultrasonication time (180 seconds) and power ( $60 \%$ amplitude). The significant positive influence of Eudragit S100 on the resultant EE would be ascribed to its hydrophobic methacrylate structure. Eudragit S100 encompasses an anionic copolymerization product of methacrylic acid and methyl methacrylate to impart a thick polymeric surface to the formed nanomicelles. Moreover, the low density of quaternary ammonium groups in Eudragit S100 would limit nicotinamide diffusion to the aqueous medium. ${ }^{27}$

Table 4 and Figure 3 show statistically insignificant but positive influence of the stabilizer, $\mathrm{MgCl}_{2}$, on the resultant EE. $\mathrm{MgCl}_{2}$ was employed as the nanodispersion's stabilizer owing to its strong affinity to the terminal carboxyl groups. This negative effect of $\mathrm{MgCl}_{2}$ on drug leakage would be described by the ion-dipole interaction that existed. Magnesium ions $\left(\mathrm{Mg}^{2+}\right)$ would bridge with the divalent ions of interacting oxygen atoms to stabilize the host drug molecule inside the micelles. After overnight stirring, aggregated particles were observed to indicate instability of the nanodispersion. This instability might be due to the strong interactions between $\mathrm{Mg}^{2+}$ ions and oxygen atoms of HP- $\beta-C D$; hence, this intermicellar bridge would result in further precipitation. Despite this insignificant adverse effect of the stabilizer on nicotinamide EE and EC, overall ANOVA results would indicate high prediction accuracy of the developed models; hence, the response surface plots, shown in Figure 4, could represent the design space for predicting and subsequent monitoring of nicotinamide EC and EE percentages. 


\section{Vesicular size and size distribution}

Table 2 shows that the size and PDI of the prepared polymeric nanoemulsified particles changed from 43.3 (F2) to $243.3 \mathrm{~nm}$ (F11) and from 0.08 (F2) to $0.28 \mathrm{~nm}$ (F12) by changing the investigated variables. Plotting the observed and predicted values of particle size and the corresponding PDI yielded linear correlations with coefficients of multiple determination $\left(R^{2}\right)$ values of 0.9534 and 0.6495 , respectively (Table 3 ). This would indicate the accuracy of the model to predict only the resultant sizes with lower efficiency to predict the corresponding PDI. ANOVA showed significant effects of both the formulation and process variables on the measured sizes with Prob $>F$ value of 0.0406 at $P<0.05$ (Table 4). On the other hand, the higher Prob $>F$ value ( 0.6982$)$ than 0.05 would indicate the poor predictability of the model to monitor the associated PDI values. The reduced prediction equation to relate individual effects with particle sizes is shown as follows:

$$
\begin{aligned}
\begin{array}{c}
\text { Particle size } \\
(\mathrm{nm})
\end{array} & 184.6+54.1 *\left(\frac{(\text { Eudragit S100 }(\mathrm{mg})-150)}{50}\right) \\
& +43.1 *\left(\frac{(\text { Drug loading }(\mathrm{mg})-30)}{10}\right) \\
& -41.08^{*}\left(\frac{(\text { Ultrasonication amplitude }(\%)-45)}{15}\right)
\end{aligned}
$$

The significant factors that affect the obtained particle size were Eudragit S100 and drug-loading concentrations, and ultrasonic amplitude. On the other hand, all the studied variables were insignificant for their effects on the corresponding PDI values. Experimental Eudragit S100 concentration was the most significant factor affecting particle size $(P=0.0196)$ followed by ultrasonic amplitude and experimental drug load (Table 4 and Figure 3). Positive relationships were obtained by increasing Eudragit S100 and drug-loading concentrations (Figure 4), with minimum particle size of $43 \mathrm{~nm}$ obtained at drug-to-Eudragit S100 weight ratio of 1:5. At highest and lowest Eudragit S100 concentrations, increase in ultrasonic amplitude was associated with a decrease in particle sizes (Figure 4). Generally, it can be expected that polymeric nanoemulsified particle size is dependent on emulsion vesicular size; hence, it can be related to the viscosity of phases of multiple emulsion. Abdelmalak and El-Menshawe attributed the positive influence of polymer concentration to the increment of polymer amount per formed particle; hence, increased viscosity of polymer solution would hinder shearing of emulsion vesicles into smaller droplets. ${ }^{28}$ The inverse correlation of particle size with ultrasonic amplitude can be described by the tendency of the emulsion globules to coalesce and aggregate at lower sonication power. On the other hand, higher sonication effects would result in faster breaking of formed vesicles and lower probability for coalescence into larger droplets. ${ }^{29}$ Despite being insignificant, HP- $\beta-C D$ contribution to decrease the resultant particle size can be explained by its inclusion potential through electrostatic, van der Waals, and hydrophobic-hydrophobic interactions, and hydrogen bonding. This would enhance the solubility, permeability, and stability of the system, and decrease the particle size. ${ }^{30}$ The significant positive effect of drug loading on the resultant sizes could also be explained by the law of mass action to entrap drug molecules within the formed stiff polymeric matrix.

\section{Zeta potential of liposomes}

For variables' combinations throughout the 12 formulations of $\mathrm{PB}$, Table 3 demonstrates that zeta potential values varied from 9.5 (F11) to $53.3 \mathrm{mV}$ (F5). The significant factors affecting surface charge intensity of the prepared polymeric nanoemulsified particles were Eudragit S100 and drug-loading concentrations, and volume of aqueous phase (Table 4 and Figure 3). Results of multiple regression analysis revealed a significant positive effect of Eudragit S100 loadings and significant negative effects of both drug-loading concentration and volume of aqueous phase on the recorded zeta potentials. Table 4 and Figure 3 show that experimental Eudragit S100 concentration was the most significant factor affecting zeta potential $(P=0.0092)$ followed by experimental drug load $(P=0.0171)$ and volume of aqueous phase $(P=0.0441)$. Zeta potential is the potential difference between the dispersion medium and the stationary layer of fluid attached to the dispersed particle. It supports the potential physical stability of the formulation. The magnitude of the zeta potential indicates the degree of electrostatic repulsion between adjacent, similarly charged particles in dispersion. It is reported that the value of $\pm 30 \mathrm{mV}$ assures the good stability of nanodispersed systems. ${ }^{31}$ All the prepared polymeric nanoemulsified particles exhibited negative charges because of surface association of the polyanionic Eudragit S100 moieties with various carboxylic end anions. The increased zeta potential values with increasing Eudragit S100 loading would be ascribed to the high viscosity of external aqueous vehicle that increases the hydrophilicity of particles. These charges might cause stronger repulsive forces among the particles; hence, higher stability of the formulation was expected. Compared to low drug loading, zeta potential values decreased by increasing experimental drug loading which might be drug loading at the micellar cavities to promote destabilization of the system. ${ }^{32}$ The negative relationship between volume of the 
aqueous phase and the detected zeta potential values could be explained by the decrease in the hydrodynamically counter charges at the particle surfaces. Overall, the developed regression model showed an acceptable predictability of zeta potential with a $P$-value of 0.0402 and quantile-quantile correlation coefficient of 0.9650 (Table 4 ). The reduced model equation to predict the zeta potential value of the liposomal dispersion is:

$$
\begin{aligned}
\begin{array}{l}
\text { Zeta potential } \\
(\mathrm{mV})
\end{array} & 31.55+8.4^{*}\left(\frac{(\text { Eudragit S100 }(\mathrm{mg})-150)}{50}\right) \\
& -6.7 *\left(\frac{(\text { Drug loading }(\mathrm{mg})-30)}{10}\right) \\
& -3.2^{*}\left(\frac{(\text { Aqueous volume }(\mathrm{mL})-60)}{20}\right)
\end{aligned}
$$

\section{Nicotinamide release}

Figure 5 shows that the release data exhibited sustained release profiles, that is, an initial burst effect followed by subsequent slower release (Figure 5). At the initial stage, the burst release is usually ascribed to the free nicotinamide associated with the interface of the nanoemulsion's hydrophobic core and/or hydrophilic corona, or even within the micelle corona compartment, hence facilitating the passive diffusion of the drug. ${ }^{33}$ The obtained release data fitted to a logarithmic time-dependent release better than Higuchi diffusion release (Figure 5). This behavior would be explained by the expanding transient boundary at the interface of either the polymer surface or HP- $\beta$-CD-adsorbed layer and the aqueous medium. ${ }^{19}$ The following is the logarithmic equation to predict the drug release rate, where $Q_{\mathrm{ti}}$ is percentage drug released after time $t$ to the receptor medium and $K$ is the
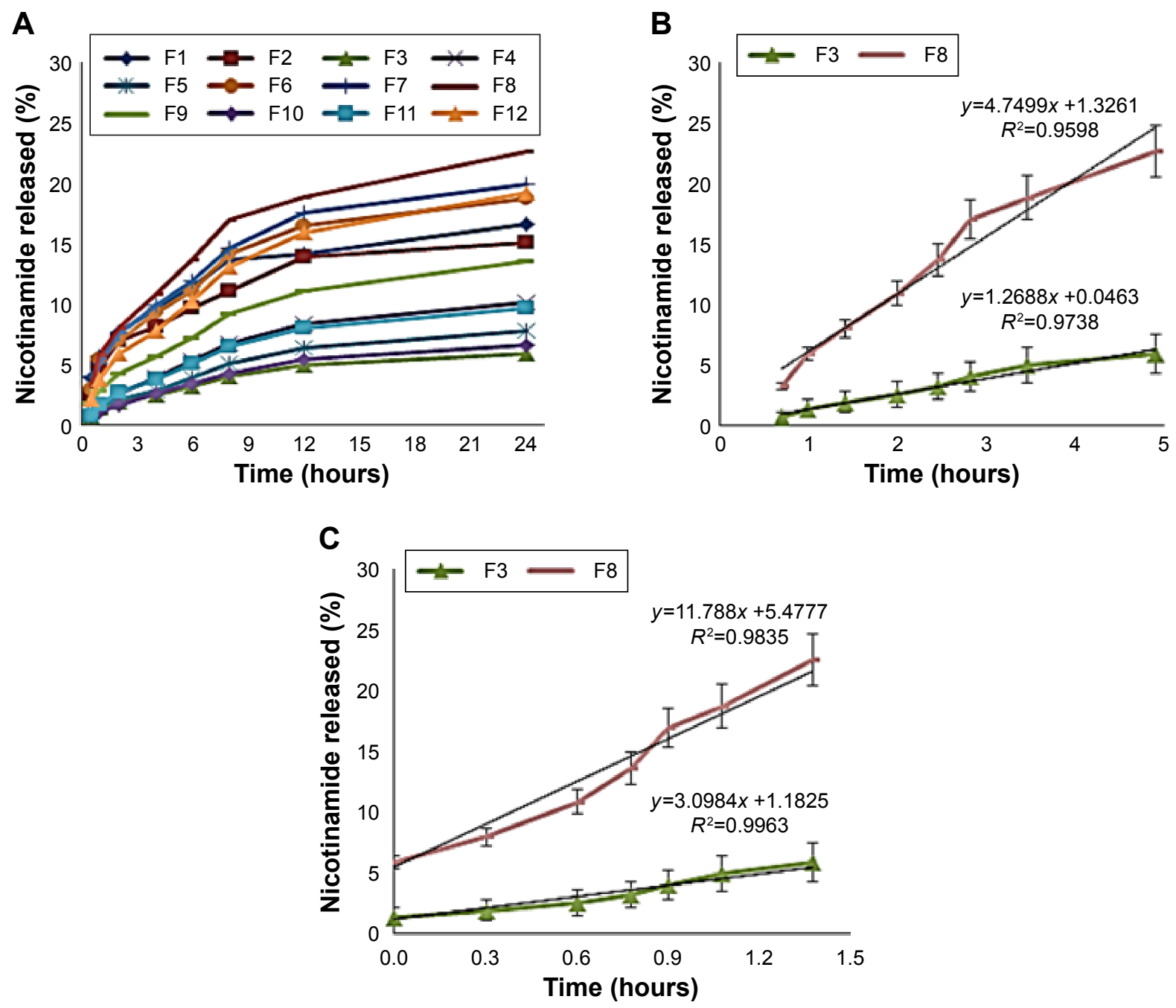

Figure 5 In vitro nicotinamide release from 12 formulations of Plackett-Burman design ( $n=3)$.

Notes: (A) Cumulative percentage of nicotinamide released in linear time scale. (B) Cumulative percentage of nicotinamide released from representative formulations F3 and F8 fitted with Higuchi model. (C) Cumulative percentage of nicotinamide released from representative formulations F3 and F8 fitted with transient-boundary model. 
release constant or the slope of plotting $Q_{\mathrm{ti}}$ versus $\log _{10} t$ divided by 2.303 .

$$
Q_{\mathrm{ti}}=\left(2.303 \times \log _{10}(t \mathrm{i}) \times K\right)+Q_{\mathrm{ti}-1}
$$

Percentage release of nicotinamide after 24 hours was nominated to represent the sustained release phase. Percentage of drug released after 24 hours varied from $5.8 \%$ (F3) to $22.4 \%$ (F8) (Table 3). As demonstrated in Figure 3 and Table 4, volume of aqueous medium and sonication parameters were significant for their effects on drug release. Higher percentages of drug released were obtained by decreasing aqueous phase volume and sonication parameters, whereas more release was found by increasing theoretical drug loading (Table 4 and Figure 4). These results can be explained by the effect of aqueous phase volume and sonication parameters to decrease both particle size and drug loading within the formed matrix. Decreasing the drug loading would result in decreasing diffusion pores and increasing path length for drug release from the particles' surfaces. On the other hand, higher HP- $\beta-C D$ at the nanoparticle solid state led to lower concentration of the solubilized drug (molecular state) in the transient layer, and consequently a lesser drug release. However, the sustained manner caused by Eudragit S100 could be attributed to the deprotonation of Eudragit carboxylic group causing swelling of the polymer and prolonged drug release.

Particle size of the formed polymeric nanoemulsified particle is also thought to impact the initial boundary layer thickness. A large size that is close to or greater than the thickness of the boundary may dramatically increase the thickness of the initial boundary layer. Despite being insignificant for the prediction model, the employed stabilizer would positively affect nicotinamide release by indirectly accelerating drug diffusion to the aqueous medium (Table 4). The developed regression model showed good predictability with $P$-values of 0.0289 for percentage of drug released in 24 hours. Moreover, quantile-quantile correlation coefficient of 0.9722 would confirm the validity for prediction (Table 4). The linear reduced model equation to predict percentage of drug released in 24 hours is given as follows:

$$
\begin{aligned}
& \text { Percentage of } \\
& \text { drug released }=13.7-1.5^{*}\left(\frac{(\text { Aqueous volume }(\mathrm{mL})-60)}{20}\right) \\
& \text { in } 24 \text { hours } \\
& -2.175 *\left(\frac{(\text { Ultrasonication time }(\mathrm{s})-135)}{45}\right) \\
& -3.9 *\left(\frac{(\text { Ultrasonication amplitude }(\%)-45)}{15}\right)
\end{aligned}
$$

\section{Solid-state analysis}

Solid-state analysis of the prepared polymeric nanoemulsified particle was done not only to understand the effect of process parameters on physical characteristics of nicotinamide but also to mine any interaction that occurred between the drug and the employed excipients. Figure 6 demonstrates DSC thermograms of nicotinamide, individual additives, and formulation F3 of highest EE and EC. The heat of fusion involved during DSC analysis was dependent on the employed powder weight. Hence, all thermograms were overlaid with normalization to $1 \mathrm{mg}$ weight. Nicotinamide thermogram showed a sharp thermal transition at $130^{\circ} \mathrm{C}$ corresponding to its melting peak. ${ }^{19}$ DSC thermogram of Eudragit S100 showed a wide endothermic transition at $50^{\circ} \mathrm{C}-118^{\circ} \mathrm{C}$, which attributed to the evaporation of the adsorbed moisture $(\Delta H=63.87 \mathrm{~J} / \mathrm{g})$. The glass thermal transition of Eudragit S100 was not detected which probably was covered by the adsorbed moisture evaporation. In general, glass transition temperature of Eudragit $\mathrm{S} 100$ is $\sim 120^{\circ} \mathrm{C}$. The DSC thermogram of HP- $\beta$-CD showed a broad endothermic transition at $60^{\circ} \mathrm{C}-150^{\circ} \mathrm{C}$ due to evaporation of water that had been absorbed by HP- $\beta$-CD. In the DSC curve of formulation $\mathrm{F} 3$ of polymeric nanoemulsified particles, the melting peak of nicotinamide disappeared, owing to the amorphous transformation of the drug or its inclusion and/or interaction with either HP- $\beta-C D$ or Eudragit S100, respectively. ${ }^{34}$ Hence, further solid-state characterization was done by FTIR and $\mathrm{XRD}$ to strengthen this hypothesis.

FTIR analysis was performed to understand any interaction between the drug and the employed excipients (Figure 6). Spectrum of nicotinamide showed characteristic peaks at $3,061 \mathrm{~cm}^{-1}$ due to $\mathrm{C}-\mathrm{H}$ stretching vibrations, and in-plane $\mathrm{C}-\mathrm{H}$ bending vibrations at $1,124,1,092$, and $1,029 \mathrm{~cm}^{-1}$. Two $\mathrm{C}=\mathrm{C}$ stretching vibrations were also observed at 1,540 and $1,480 \mathrm{~cm}^{-1}$. Two $\mathrm{C}-\mathrm{C}$ stretching vibrations at 1,420 and $1,350 \mathrm{~cm}^{-1}$, two $\mathrm{C}-\mathrm{C}-\mathrm{C}$ bending vibrations at 625 and $603 \mathrm{~cm}^{-1}, \mathrm{C}=\mathrm{N}$ stretching vibration at $1,575 \mathrm{~cm}^{-1}$, $\mathrm{C}-\mathrm{N}$ stretch at $1,340 \mathrm{~cm}^{-1}$, two $\mathrm{N}-\mathrm{H}$ stretching vibrations at 3,367 and $3,158 \mathrm{~cm}^{-1}$, two $\mathrm{N}-\mathrm{H}$ in-plane bending vibrations at 1,580 and $1,593 \mathrm{~cm}^{-1}, \mathrm{C}=\mathrm{O}$ stretch at $1,698 \mathrm{~cm}^{-1}$, in-plane $\mathrm{C}=\mathrm{O}$ bending vibration at $703 \mathrm{~cm}^{-1}$, and out-ofplane $\mathrm{C}=\mathrm{O}$ bending vibration at $511 \mathrm{~cm}^{-1}$ were also shown for nicotinamide.$^{35}$ FTIR spectrum of Eudragit S100 shows characteristic stretches of $\mathrm{C}-\mathrm{H}$ at 2,990 and 2,963 $\mathrm{cm}^{-1}$, a strong $\mathrm{C}=\mathrm{O}$ stretch at $1,734 \mathrm{~cm}^{-1}$, and two esteric $\mathrm{C}-\mathrm{O}$ bands at 1,263 and $1,142 \mathrm{~cm}^{-1}$. Spectra of HP- $\beta-C D$ raw material demonstrated broad characteristic $\mathrm{O}-\mathrm{H}$ stretch at $3,354 \mathrm{~cm}^{-1}$, $\mathrm{C}-\mathrm{H}$ stretch at $2,962 \mathrm{~cm}^{-1}$, and $\mathrm{C}-\mathrm{H}$ and $\mathrm{C}-\mathrm{O}$ stretches at 

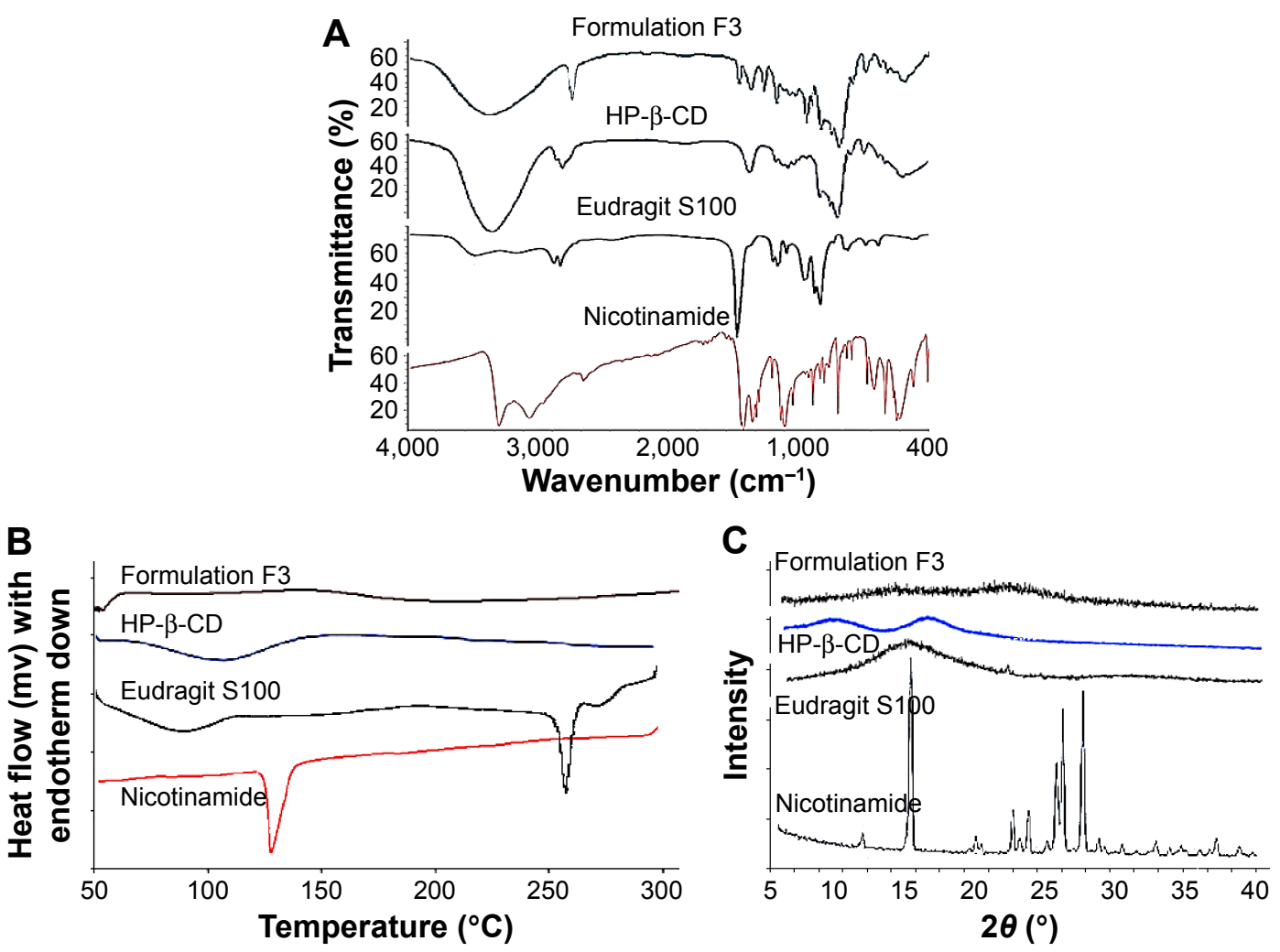

Figure 6 Compatibility analysis of nicotinamide with the investigated excipients.

Notes: (A) FTIR, (B) DSC, and (C) XRD data for the nicotinamide-loaded polymeric nanoemulsified particles (batch F3) and raw materials.

Abbreviations: FTIR, Fourier transform infrared spectroscopy; DSC, differential scanning calorimetry; XRD, X-ray diffraction; HP- $\beta$-CD, 2-hydroxypropyl- $\beta$-cyclodextrin.

1,134 and $1,079 \mathrm{~cm}^{-1}$. The FTIR spectrum of formulation F3 showed that the absorption bands at 1,698, 1,540, and $1,480 \mathrm{~cm}^{-1}$ of nicotinamide red-shifted to $1,690,1,534$, and $1,471 \mathrm{~cm}^{-1}$, respectively, and their intensities notably decreased. Simultaneously, the absorption peaks of HP- $\beta-C D$ at 2,962 and $1,079 \mathrm{~cm}^{-1}$ were also detected with slight redshift and decreased intensity. Moreover, the characteristic $\mathrm{O}-\mathrm{H}$ stretch became broader to indicate that nicotinamide and HP- $\beta-C D$ interacted with each other through hydrogen bonding inside the hydrophobic cavity of HP- $\beta-C D$. This is in accordance with the findings of Prabhu et al who suggested that this molecular modeling would contribute to stabilizing the drug-HP- $\beta-C D$ complexes. ${ }^{36}$ The obtained results of XRD analysis (Figure 6) confirm this interaction. XRD diffractogram of the polymeric nanoemulsified particles showed a hollow pattern with disappearance of nicotinamide characteristic peaks at 12.2, 15.3, 23.7, 24.3, 26.4, 26.9, and $28.42 \theta$ degrees. This would indicate the formation of a new solid phase with amorphous nature. Hence, the obtained DSC, XRD, and FTIR data would indicate that HP- $\beta-C D$ interaction with the drug contributed to the resultant solid phase as well as stabilized the formed polymeric nanoemulsified particles.

\section{Antibacterial screening test}

The in vitro antimicrobial screening of nicotinamide raw material and its polymeric nanoemulsions was performed against the bacterial scrums, viz B. subtilis, S. aureus, $E$. coli, and $P$. aeruginosa. Since DMSO was employed as a dispersion medium, it was also screened for its antibacterial activity against the organisms, and no significant antibacterial activity was observed at $P<0.05$. The MIC values of different formulations (F1-F12) of PB against the growth of the four bacterial strains are summarized in Table 5. The obtained MIC values for the 12 formulations would demonstrate their potential antibacterial activities with some variations. Furthermore, as the equivalent concentration of nicotinamide in the formulations increased from 100 to $200 \mu \mathrm{g} / \mathrm{mL}$, the inhibition zones in the bacterial scrum were also found to be increased. In general, the formulations were found to be enforced potentially on par with the nicotinamide contents against the same type of bacteria and under the same experimental conditions.

The increase in efficiency among the formulations can be attributed to their capacity to release their nicotinamide contents over time. Hence, as percentage of nicotinamide released was increased, the participation of the formulations on the 
Table 5 Antibacterial activity of the prepared nicotinamide-loaded polymeric nanoemulsified particles - diameter of zone of inhibition (in $\mathrm{mm}$ )

\begin{tabular}{|c|c|c|c|c|c|c|c|c|}
\hline \multirow[t]{2}{*}{ Batch No } & \multicolumn{2}{|c|}{ Bacillus subtilis } & \multicolumn{2}{|c|}{ Staphylococcus aureus } & \multicolumn{2}{|c|}{ Escherichia coli } & \multicolumn{2}{|c|}{ Pseudomonas aeruginosa } \\
\hline & $100 \mu \mathrm{g} / \mathrm{mL}$ & $200 \mu \mathrm{g} / \mathrm{mL}$ & $100 \mu \mathrm{g} / \mathrm{mL}$ & $200 \mu \mathrm{g} / \mathrm{mL}$ & $100 \mu \mathrm{g} / \mathrm{mL}$ & $200 \mu \mathrm{g} / \mathrm{mL}$ & $100 \mu \mathrm{g} / \mathrm{mL}$ & $200 \mu \mathrm{g} / \mathrm{mL}$ \\
\hline Nicotinamide & 3.72 & 4.65 & 12.60 & 16.80 & 7.00 & 11.20 & 8.40 & 12.60 \\
\hline FI & 11.16 & 13.94 & 12.55 & 16.73 & 6.97 & 11.16 & 8.37 & 12.55 \\
\hline $\mathrm{F} 2$ & 10.08 & 12.60 & II.34 & 15.12 & 6.30 & 10.08 & 7.56 & 11.34 \\
\hline F3 & 3.90 & 4.87 & 4.38 & 5.85 & 2.44 & 3.90 & 2.92 & 4.38 \\
\hline F4 & 6.79 & 8.48 & 7.64 & 10.18 & 4.24 & 6.79 & 5.09 & 7.64 \\
\hline F5 & 5.17 & 6.47 & 5.82 & 7.76 & 3.23 & 5.17 & 3.88 & 5.82 \\
\hline F6 & 12.50 & 15.62 & 14.06 & 18.75 & 7.81 & 12.50 & 9.37 & 14.06 \\
\hline F7 & $|3.3|$ & 16.63 & 14.97 & 19.96 & 8.32 & $|3.3|$ & 9.98 & 14.97 \\
\hline F8 & 15.05 & 18.32 & 16.93 & 22.58 & 9.41 & 15.05 & 11.29 & 16.93 \\
\hline F9 & 9.00 & 11.26 & 10.13 & $|3.5|$ & 5.63 & 9.00 & 6.75 & 10.13 \\
\hline FIO & 4.37 & 5.46 & 4.91 & 6.55 & 2.73 & 4.37 & 3.28 & 4.91 \\
\hline FII & 6.45 & 8.06 & 7.26 & 9.68 & 4.03 & 6.45 & 4.84 & 7.26 \\
\hline $\mathrm{FI} 2$ & 12.90 & 16.13 & 14.52 & 19.35 & 8.06 & 12.90 & 9.68 & 14.52 \\
\hline
\end{tabular}

Note: Relative standard deviations did not exceed $15 \%$ of the stated values.

demolition of bacterial cell process also increased. For example, formulation F8 released 22.4\% nicotinamide in 24 hours, and its incubation with bacterial scrums at $100 \mu \mathrm{g} / \mathrm{mL}$ showed MIC values of $15.05,16.93,9.41$, and $11.29 \mathrm{~mm}$ for $B$. subtilis, $S$. aureus, E. coli, and P. aeruginosa, respectively. On the other hand, formulation $\mathrm{F} 3$ released 5.8\% nicotinamide in 24 hours, and its incubation with bacterial scrums at $100 \mu \mathrm{g} / \mathrm{mL}$ showed MIC values of 3.90, 4.38, 2.44, and $2.92 \mathrm{~mm}$ for $B$. subtilis, $S$. aureus, E. coli, and P. aeruginosa, respectively. The process of entrapping nicotinamide within these polymeric nanoemulsified particles considerably reduces the availability and hence the clearance of nicotinamide by bacterial cells. Thus, the formulations would provide a sustained antibacterial activity that depends on nicotinamide loading concentration and incubation time. Furthermore, it would be speculated that the formulation components would interact chemically with the active centers of organisms' cell constituents resulting in the perturbation of the normal cell respiratory process of the microbe. Thus, formulating nicotinamide into a polymeric nanoemulsified systems would enhance the penetration and hence the rate of uptake/ entrance into microbial cells. ${ }^{37}$ Further studies are in progress to understand the penetration and uptake/entrance mechanisms.

\section{Conclusion}

Nicotinamide-loaded polymeric nanoemulsified particles were successfully prepared by $\mathrm{O} / \mathrm{W}$ emulsification technique followed by organic phase evaporation. Formulation and process factors were screened using a PB approach to understand and rank the most important variables affecting the critical characteristics of the systems. The QTPP and CQAs of a target gel product of nicotinamide-loaded polymeric nanoemulsified particles were also presented. The in vitro release studies showed a sustained release profile with particle sizes $<240 \mathrm{~nm}$. Among eight formulation and process variables investigated, the experimental loadings of HP- $\beta-C D$ and Eudragit S100 were the most significant for their effects on nicotinamide EC and EE. The FTIR, DSC, and XRD revealed a significant interaction between the drug and HP- $\beta-C D$ that might modulate the sustained release behavior. Moreover, formulating nicotinamide into polymeric nanoemulsified systems provided a sustained antibacterial activity against bacterial scrums. Consequently, the study concludes that this polymeric nanoemulsified system could be considered as an efficient tool to sustain the antibacterial activity of nicotinamide with a patient compliance potential.

\section{Acknowledgments}

This project was funded by the Deanship of Scientific Research (DSR) at King Abdulaziz University, Jeddah, under grant No (12 - 166 - 1436 - G). The authors, therefore, acknowledge with thanks DSR technical and financial support.

\section{Disclosure}

The authors report no conflicts of interest in this work.

\section{References}

1. Khodaeiani E, Fouladi RF, Amirnia M, Saeidi M, Karimi ER. Topical $4 \%$ nicotinamide vs. $1 \%$ clindamycin in moderate inflammatory acne vulgaris. Int J Dermatol. 2013;52(8):999-1004.

2. Caton PW, Kieswich J, Yaqoob MM, Holness MJ, Sugden MC. Nicotinamide mononucleotide protects against pro-inflammatory cytokine-mediated impairment of mouse islet function. Diabetologia. 2011;54(12):3083-3092. 
3. Jafary H, Ahmadian S, Soleimani M. The enhanced apoptosis and antiproliferative response to combined treatment with valproate and nicotinamide in MCF-7 breast cancer cells. Tumour Biol. 2014;35(3):2701-2710.

4. Murray MF. Nicotinamide: an oral antimicrobial agent with activity against both Mycobacterium tuberculosis and human immunodeficiency virus. Clin Infect Dis. 2003;36(4):453-460.

5. Evered DF, Sadoogh-Abasian F, Patel PD. Absorption of nicotinic acid and nicotinamide across human buccal mucosa in vivo. Life Sci. 1980;27(18):1649-1651.

6. Pumpo R, Sarnelli G, Spinella A, Budillon G, Cuomo R. The metabolism of nicotinamide in human liver cirrhosis: a study on $\mathrm{N}$-methylnicotinamide and 2-pyridone-5-carboxamide production. Am J Gastroenterol. 2001;96(4):1183-1187.

7. Bernier J, Stratford MR, Denekamp J, et al. Pharmacokinetics of nicotinamide in cancer patients treated with accelerated radiotherapy: the experience of the Co-operative Group of Radiotherapy of the European Organization for Research and Treatment of Cancer. Radiother Oncol. 1998;48(2):123-133.

8. Janssens GO, Terhaard CH, Doornaert PA, et al. Acute toxicity profile and compliance to accelerated radiotherapy plus carbogen and nicotinamide for clinical stage T2-4 laryngeal cancer: results of a phase III randomized trial. Int J Radiat Oncol Biol Phys. 2012;82(2):532-538.

9. Salerno A, Saurina J, Domingo C. Supercritical CO foamed polycaprolactone scaffolds for controlled delivery of 5-fluorouracil, nicotinamide and triflusal. Int J Pharm. 2015;496(2):654-663.

10. Fan X, Chen J, Shen Q. Docetaxel-nicotinamide complex-loaded nanostructured lipid carriers for transdermal delivery. Int J Pharm. 2013;458(2):296-304.

11. Yu H, Xia D, Zhu Q, Zhu C, Chen D, Gan Y. Supersaturated polymeric micelles for oral cyclosporine A delivery. Eur J Pharm Biopharm. 2013; 85(3 Pt B):1325-1336.

12. Gaucher G, Satturwar P, Jones MC, Furtos A, Leroux JC. Polymeric micelles for oral drug delivery. Eur J Pharm Biopharm. 2010;76(2): 147-158.

13. Chang SF, Chang HY, Tong YC, et al. Nonionic polymeric micelles for oral gene delivery in vivo. Hum Gene Ther. 2004;15(5):481-493.

14. Zhang Q, Vakili MR, Li XF, Lavasanifar A, Le XC. Polymeric micelles for GSH-triggered delivery of arsenic species to cancer cells. Biomaterials. 2014;35(25):7088-7100.

15. Francis MF, Cristea M, Winnik FM. Exploiting the vitamin B12 pathway to enhance oral drug delivery via polymeric micelles. Biomacromolecules. 2005;6(5):2462-2467.

16. Velasquez AD, Ferreira LM, Stangarlin MFL, da Silva CD, Rolim CMB, Cruz L. Novel Pullulan-Eudragit (R) S100 blend microparticles for oral delivery of risedronate: formulation, in vitro evaluation and tableting of blend microparticles. Mater Sci Eng C Mater Biol Appl. 2014;38:212-217.

17. Khan MZI, Stedul HP, Kurjakovic N. A pH-dependent colon-targeted oral drug delivery system using methacrylic acid copolymers. II. Manipulation of drug release using Eudragit (R) L100 and Eudragit S100 combinations. Drug Dev Ind Pharm. 2000;26(5):549-554.

18. Peterson JJ. A Bayesian approach to the ICH Q8 definition of design space. J Biopharm Stat. 2008;18(5):959-975.

19. Zidan AS, Ebeed M, Elghamry H, Badawy A. Nicotinamide pelletization by fluidized hot melt granulation: L18 Hunter design to screen high risk variables. Int J Pharm. 2014;466(1-2):83-95.
20. Coaker H. EMA and US FDA release initial conclusions of parallel assessment of quality-by-design applications. Future Med Chem. 2014; 6(9):985.

21. Badawy SI, Narang AS, LaMarche KR, et al. Integrated application of quality-by-design principles to drug product development: a case study of brivanib alaninate film-coated tablets. J Pharm Sci. 2016;105(1):168-181.

22. Revelli A-L, Laugier S, Erriguible A, Subra-Paternault P. High-pressure solubility of naproxen, nicotinamide and their mixture in acetone with supercritical CO2 as an anti-solvent. Fluid Phase Equilib. 2014;373: 29-33.

23. Dilip CS, Kumar VS, Venison SJ, Potheher IV, Rajalaxmi D. Synthesis, structural characterisation, bio-potential efficiency and DNA cleavage applications of nicotinamide metal complexes. J Mol Struct. 2013;1040:192-205.

24. Ferreira AP, Tobyn M. Multivariate analysis in the pharmaceutical industry: enabling process understanding and improvement in the PAT and QbD era. Pharm Dev Technol. 2015;20(5):513-527.

25. Jiang MW, Guo CG, Wang L, Wang CQ. Multi-morphological selfassembled structures in water of a biodegradable beta-cyclodextrinbased copolymer. Carbohydr Polym. 2012;90(2):1046-1054.

26. Lopedota A, Trapani A, Cutrignelli A, et al. The use of Eudragit (R) RS 100/cyclodextrin nanoparticles for the transmucosal administration of glutathione. Eur J Pharm Biopharm. 2009;72(3):509-520.

27. Nath B, Nath LK, Kumar P. Preparation and in vitro dissolution profile of zidovudine loaded microspheres made of Eudragit RS 100, RL 100 and their combinations. Acta Pol Pharm. 2011;68(3):409-415.

28. Abdelmalak NS, El-Menshawe SF. A new topical fluconazole microsponge loaded hydrogel: preparation and characterization. Int J Pharm Pharm Sci. 2012;4(1):460-469.

29. Jain V, Singh R. Dicyclomine-loaded Eudragit (R)-based microsponge with potential for colonic delivery: preparation and characterization. Trop J Pharm Res. 2010;9(1):67-72.

30. Volltexte SAFAB. Cyclodextrins as drug carrier molecule: a review. Sci Pharm. 2008;76:567-598.

31. Adamczyk Z, Zaucha M, Zembala M. Zeta potential of mica covered by colloid particles: a streaming potential study. Langmuir. 2010; 26(12):9368-9377.

32. Gupta S, Kesarla R, Omri A. Formulation strategies to improve the bioavailability of poorly absorbed drugs with special emphasis on self-emulsifying systems. ISRN Pharm. 2013;2013:848043.

33. Zhang JX, Ellsworth K, Ma PX. Hydrophobic pharmaceuticals mediated self-assembly of beta-cyclodextrin containing hydrophilic copolymers: novel chemical responsive nano-vehicles for drug delivery. J Control Release. 2010;145(2):116-123.

34. Mennini N, Bragagni M, Maestrelli F, Mura P. Physico-chemical characterization in solution and in the solid state of clonazepam complexes with native and chemically-modified cyclodextrins. J Pharm Biomed Anal. 2014;89:142-149.

35. Bayarı S, Ataç A, Yurdakul Ş. Coordination behaviour of nicotinamide: an infrared spectroscopic study. J Mol Struct. 2003;655(1):163-170.

36. Prabhu AA, Venkatesh G, Rajendiran N. Unusual spectral shifts of imipramine and carbamazepine drugs. J Fluoresc. 2010;20(6): 1199-1210

37. Arjmand F, Mohani B, Ahmad S. Synthesis, antibacterial, antifungal activity and interaction of CT-DNA with a new benzimidazole derived Cu(II) complex. Eur J Med Chem. 2005;40(11):1103-1110.
International Journal of Nanomedicine

\section{Publish your work in this journal}

The International Journal of Nanomedicine is an international, peerreviewed journal focusing on the application of nanotechnology in diagnostics, therapeutics, and drug delivery systems throughout the biomedical field. This journal is indexed on PubMed Central, MedLine, CAS, SciSearch ${ }^{\circledR}$, Current Contents ${ }^{\circledR} /$ Clinical Medicine,

\section{Dovepress}

Journal Citation Reports/Science Edition, EMBase, Scopus and the Elsevier Bibliographic databases. The manuscript management system is completely online and includes a very quick and fair peer-review system, which is all easy to use. Visit http://www.dovepress.com/ testimonials.php to read real quotes from published authors. 